\title{
ANALISIS DAN PENGEMBANGAN INFRASTRUKTUR JARINGAN KOMPUTER DALAM MENDUKUNG IMPLEMENTASI SEKOLAH DIGITAL
}

\author{
Yudi Mulyanto ${ }^{*}$, Kudratullah ${ }^{2}$ \\ 1), 2),3)Program Studi Informatika, Universitas Teknologi Sumbawa \\ 1Mulyanto.yudi@gmail.com , ${ }^{2}$ Kudrat27iradat@gmail.com
}

\begin{abstract}
Abstraksi
Sekolah Dasar (SD) merupakan suatu lembaga pendidikan tingkat dasar yang menjadi rumah edukasi bagi peserta didik. SD Negeri 2 Sumbawa Besar merupakan salah satu Sekolah Dasar Negeri yang ada di Kabupaten Sumbawa, Provinsi Nusa Tenggara Barat yang memperoleh predikat Sekolah Rujukan Nasional telah menerapkan teknologi informasi dalam proses belajar mengajar. Penelitian ini bertujuan mengembangkan infrastruktur jaringan komputer, pada SD Negeri 2 Sumbawa. Penelitian ini dikembangkan menggunakan perangkat jaringan seperti Router Mikrotik, windows Server 2012, dan perangkat jaringan pendukung lainya Metode pengembangan jaringan menggunakan metode Nerwork Developmen Life Cycle (NDLC). Dimulai dengan proses analisa, perancangan, simulasi, implementasi, monitoring hingga manajemen. Instrumen Teknik pengumpulan data pada penelitian menggunakan observasi, wawancara, dokumentasi dan studi pustaka. Hasil akhir dari penelitian ini adalah infrastruktur jaringan komputer yang telah mencover seluruh wilayah sekolah. sehingga SD Negeri 2 Sumbawa Besar mampu menerapkan aktifitas digitalisasi dan pengembangan kemampuan ilmu pengetahun dan teknologi kepada seluruh warga sekolah
\end{abstract}

Kata Kunci: SD Digital, Router Mikrotik, Server,NDLC.

\begin{abstract}
Elementary School (SD) is a basic level educational institution that is home to education for students. Sumbawa Besar 2 Elementary School is one of the Public Elementary Schools in Sumbawa Regency, West Nusa Tenggara Province which has received the title of National Referral School that has applied information technology in the teaching and learning process. This research aims to develop computer network infrastructure, at SD Negeri 2 Sumbawa. This research was developed using network devices such as Mikrotik Router, Windows Server 2012, and other supporting network devices. Network development methods use the Nerwork Developmen Life Cycle (NDLC). Starting with the process of analysis, design, simulation, implementation, monitoring and management. Instruments Data collection techniques in research using observation, interviews, documentation and literature. The final result of this study is a computer network infrastructure that has covered the entire school area. so Sumbawa Besar Elementary School 2 is able to apply digitalization and development of knowledge and technology capabilities to all school members
\end{abstract}

Keywords: SD Digital, Mikrotik Router, Server, NDLC.

\section{PENDAHULUAN}

Perkembangan teknologi informasi menjadi kebutuhan dalam menunjang aktivitas manusia saat ini terutama dalam bidang pendidikan. Pendidikan di Indonesia sudah berkembang pesat beberapa tahun belakangan, mulai dari tingkat sekolah dasar, sekolah menengah hingga tingkat universitas.

SD Negeri 2 Sumbawa Besar merupakan satusatunya SD Rujukan di Kabupaten Sumbawa menurut keputusan Direktorat Jenderal Pendidikan Dasar dan Menengah Kementerian Pendidikan dan Kebudayaan Republik Indonesia Nomor:267/C/KL/2015. Sebagai SD Rujukan Nasional tentunya telah menerapkan teknologi infomasi dalam menunjang aktivitas belajar mengajar, penilaian, pengembangan skill dan branding sekolah. Hal ini dibuktikan dengan pelaksanaan tryout online, pembelajaran berbasis edmodo, penilaian digital digunakan oleh masingmasing wali kelas, pelaksanaan workshop nasional berbasis online untuk para guru dan pemampaatan website sebagi media promosi sekolah, dikarenakan hal tersebut maka SD Negeri 2 Sumbawa Besar disebut SD digital.

Dalam mendukung aktifitas digitalisasi di sekolah tersebut membutuhkan jaringan komputer yang lebih reliabel dan funsional. Sementara jaringan yang ada saat ini hanya melayani satu Local Area Network (LAN) dengan kebutuhan internet. Hal ini membatasi ruang gerak siswa dan guru dalam bertukar informasi, belajar dalam jaringan (daring) dan penggunaan sumber daya (resource)

Untuk itu dibutuhkan pengembangan jaringan komputer yang lebih baik untuk mendukung implementasi sekolah digital dengan penyedian layanan jaringan di semua tempat, sehingga siswa 
maupun guru dapat saling bertukar informasi dengan pengunaan sumber daya bersama. Maka peneliti mengambil judul "Analisis Dan Pengembangan Jaringan Komputer Dalam Mendukung Implementasi Sekolah Digital : Studi Kasus SD Negeri 2 Sumbawa Besar.

Dengan adanya jaringan komputer yang lebih reliabel dan fungsional sebagaimana dalam rancangan yang dilakukan oleh peneliti akan memudahkan pihak sekolah dalam bertukar data atau informasi, efisiensi penggunaan perangkat, dan meningkatkan kapasitas guru dan siswa karena telah menerapkan sistem pembelajaran dalam jaringan (daring) berbasis komputer.

\section{TINJAUAN PUSTAKA}

\subsection{Tinjauan Pustaka}

Esabella (2016) "Perancangan Infrastruktur Jaringan Komputer Untuk Mendukung Implementasi Sistem Informasi Pada Universitas Teknologi Sumbawa”. Terdapat kesesuaian antara penelitian yang dilakukan Esabella dengan penelitian yang dilakuakan oleh penulis, kesamaan tersebut yaitu fokus penelitian yang dilakukan adalah berorientasi pada pembenahan infrastruktur dan metode yang digunakan adalah metode Network Development Life Cycle (NDLC). Sedangkan perbedaan dari penelitian ini adalah pada objek yang diteliti dan pada tahap penerapan atau implementasi, Esabella melakukan penelitian dan implementasi menggunakan simolator sedangkan penulis melakukan penelitian dan implementasi langsung dilapangan.

\subsection{Dasar Teori}

\subsubsection{Analisis.}

Menurut Harahap (2004) mendefinisikan bahwa analisis adalah memecahkan atau menguraikan sesuatu unit menjadi berbagai unit terkecil. Sehingga dapat dilakukan pengolahan terhadap unitunit tersebut.

\subsubsection{Pengembangan.}

Menurut pendapat Sujadi (2002) menjelaskan bahwa penelitian dan pengembangan merupakan proses atau langkah untuk mengembangkan suatu produk baru, untuk menyempurnakan produk yang sudah ada, yang bisa dipertanggungjawabkan.

\subsubsection{Infrastruktur.}

Menurut Kodoatie (2005) infrastruktur dalam sebuah sistem adalah bagian-bagian berupa sarana dan prasarana (jaringan) yang tidak terpisahkan satu sama lain. Infrastruktur sendiri dalam sebuah sistem menopang sistem sosial dan sistem ekonomi sekaligus menjadi penghubung dengan sistem lingkungan.

\subsubsection{Jaringan Komputer.}

Menurut Kriston (2003) dapat diartikan sebagai kumpulan sejumlah terminal komunikasi yang terdiri dari dua komputer atau lebih yang saling terhubung. Tujuan dibangunnya jaringan komputer adalah agar informasi atau data yang dibawa pengirim (transmitter) dapat sampai kepada penerima (receiver) dengan tepat dan akurat. Jaringan komputer memungkinkan penggunanya dapat melakukan komunikasi satu sama lain dengan mudah. Selain itu, peran jaringan komputer sangat diperlukan untuk mengintegrasi data antar komputer-komputer client sehingga diperolehlah suatu data yang relevan.

\subsubsection{Impelementasi.}

Menurut Usman (2002) berpendapat bahwa implementasi bermuara pada aktivitas, aksi, tindakan, atau adanya mekanisme suatu sistem. Implementasi bukan sekedar aktivitas, tetapi suatu kegiatan yang terencana dan untuk mencapai tujuan kegiatan

\subsubsection{Sekolah Digital.}

Menurut Mahmud (2017) sekolah digital adalah segala usaha untuk mengubah sumber daya sekolah yang ada ke dalam bentuk digital berbasis internet , melalui alat atau instrumen yang canggih, sedemikian rupa sehingga kehidupan nyata sekolah dapat ditingkatkan melebihi waktu maupun ruang yang ada.

\section{MATODOLOGI PENELITIAN}

\subsection{Matodologi Penelitian}

Dalam melakukan penelitian di SD Negeri 2 Sumbawa Besar dengan judul Analisis Dan Pengembangan Jaringan Komputer Dalam Mendukung Implementasi Sekolah Digital. Adapun tahapan-tahapan yang dilakukan dalam pengembangan jaringan ini sebagai berikut:

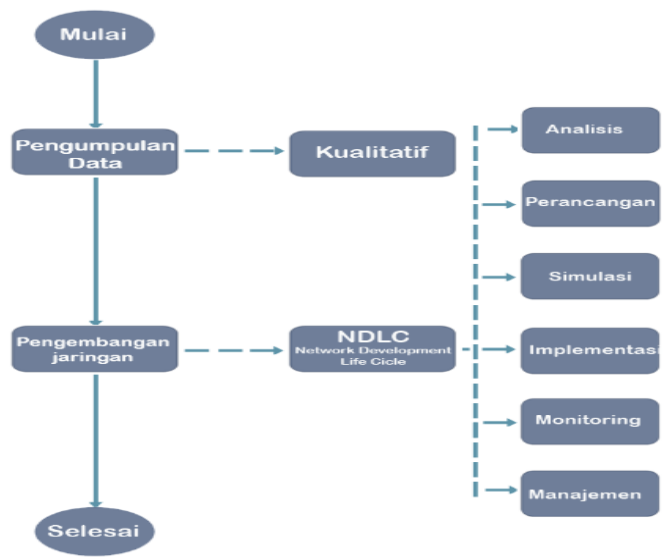

Gambar 3.1 Tahapan-Tahapan Metode Penelitian 


\subsubsection{Metode Pengumpulan Data.}

1) Observasi adalah tahap melakukan survei lokasi untuk mengumpulkan data-data SD Negeri 2 Sumbawa. Survei ini dilakukan untuk mencari data jaringan dan data pengguna jaringan.

2) Wawancara adalah tahap melakukan wawancara terhadap kepala sekolah dan kepala IT SD Negeri 2 Sumbawa Besar, untuk mendapatkan informasi terkait perkembangan dan fungsi keberadaan jaringan komuputer.

3) Dokumentasi adalah tahapan dimana peneliti mengambil data berupa gambar atau foto dari beberapa lokasi strategsi utnuk menempatkan perangkat yang nantinya akan melayani seluruh area sekolah.

4) Studi Pustaka adalah tahap ini peneliti mempelajari konsep, teknik, maupun informasi dari berbagai sumber seperti internet, buku, jurnal, maupun artikel ilmiah lainnya yang berkaitan dengan jaringan komputer.

\subsubsection{Metode Pengembangan Jaringan.}

Penelitian ini menggunakan metode pengembangan jaringan Network Development Life Cycle (NDLC) terdiri dari enam tahapan yaitu analisis, perancangan, simulasi prototype, penerapan. monitoring, dan manajemen

\subsubsection{Gambaran Umum Objek Penelitian.}

SD Negeri 2 Sumbawa Besar merupakan sekolah digital predikat terakreditasi A yang berada di kabupaten sumbawa. Telah beroperasi sejak tahun 1939 dengan luas tanah 3.980 meter persegi, nomor statistik sekolah 101230401002. Sekolah tersebut memiliki setandar gedung permanen dengan luas bangunan 1253 meter persegi yang tediri dari tujuh unit gedung sekolah, 15 ruang belajar dan 31 pendidik dan tenaga kependidikan serta sebanyak 570 peserta didik pada tahun ajaran 2017/2018.

\subsection{Analisis dan Perancangan}

Analisis dan perancangan dibagi menjadi empat bagian yaitu

\subsubsection{Analisis Masalah Arsitektur Sistem Jaringan.}

Jaringan di SD Negeri 2 Sumbaa Besar secara geografis termasuk dalam kategori Local Area Network dengan media transmisi menggunakan wireless dan topologi yang ada saat ini adalah topologi star, pada jaringan tersebut belum ada distrtibusi sumber informasi atau data dan belum terbangunnya hubungan tiap komputer dalam pemrosesan data serta pemanfaatan jaringan komputer hanya untuk mengakses internet. Berikut gambar topologi yang ada saat ini.

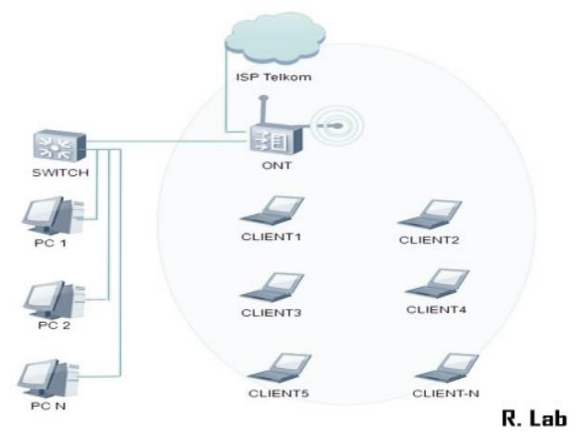

Gambar 3.2 Topologi Yang Digunakan Saat Ini

\subsubsection{Rangkaian/Diagram Jaringan.}

Dalam merancang dan membangun jaringan komputer di SD Negeri 2 Sumbawa Besar, peneliti akan menggunakan topologi tree. Hal ini dilakukan karena pengembangan dari topologi awal (topologi star) yang bersifat fleksibel sehingga perubahan menjadi topologi tree cukup mudah. Selain itu penerapan topologi tree juga didasarkan pada keunggulanya yaitu susunan data terpusat secara hirarki, hal tersebut membuat manajemen data lebih baik dan mudah. Topologi tree juga memberikan kemudahan bagi peneliti jika sewaktu waktu jaringan akan kembali dikembangkan menjadi jaringan yang lebih luas lagi. Karena tidak menutup kemungkinan teknologi kedepan akan menuntut perkembangan jaringan komputer dalam mendukung implementasinya.

\subsubsection{Strategi Pemecahan Masalah.}

Dalam melakukan pemecahan masalah, peneliti menerapkan konfigurasi pada perangkat router dan server yang akan mengatur layanan serta jalur routing dari masing masing client yang terhubung. Penggunaan topologi tree manjadikan jaringan lebih fleksibel dalam pengembangan dan penambahan perangkat yang akan membantu dari segi maintenance.

\subsubsection{Gambaran Garis Besar dari Perangkat Jaringan.}

Secara umum perangkat yang akan digunakan dalam mengembangkan jarinan komputer di SD Negeri 2 Sumbawa Besar terdiri dari perangkat keras (hardware) perangkat lunak (software) dan pengguna. Perangkat keras yang akan digunakan adalah router, switch, acces point, komputer server, komputer clientt dan kabel jaringan. Sementara perangkat lunak yang digunakan adalah sistem operasi, browser, aplikasi controller, cloud app. 


\section{HASIL DAN PEMBAHASAN}

Adapun penerapan dari hasil metode Network Development Life Cicle (NDLC) yang telah digunakan sampai dengan tahap management pada penelitian ini adalah seabgai berikut.

\subsection{Analisis}

Dari proses analisis yang dilakukan dijabarkan dalam beberapan point analisis terkait dengan analisis kebutuhan perangkat, kebutuhan pengguna dan kebutuhan layanan yang digunakan dijabarkan sebagia berikut:

\subsubsection{Analisis Kebutuhan Perangkat Keras} (Hardware).

Tabel 4.1 Spesifikasi Perangkat Keras

\begin{tabular}{|c|c|c|}
\hline NO & $\begin{array}{l}\text { Perangkat keras } \\
\text { yang digunakan }\end{array}$ & Spesifikasi \\
\hline 1 & Komputer Server & $\begin{array}{l}\text { Minimal processor Intel core } \\
i 3, \text { RAM } 4 \text { GB, Harddiks : } 500 \\
G B\end{array}$ \\
\hline 2 & Komputer Client & $\begin{array}{l}\text { Minimal processor Intel } \\
\text { Pentium, RAM } 1 \mathrm{~GB}, \text { Hardisk } \\
100 \mathrm{~GB}\end{array}$ \\
\hline 3 & Router & $\begin{array}{l}\text { Router Mikrotik } \\
\text {, Gigabit Router VPN } \\
, 5 \text { port }\end{array}$ \\
\hline 4 & Switch & $\begin{array}{l}\text { TP-LINK } \\
\text { TL-SF1016D, } 16 \text { Port }\end{array}$ \\
\hline 5 & Acces point & $\begin{array}{l}\text { Tp-LINK, TL-WA7210N } \\
\text { 150mbps, Outdoor }\end{array}$ \\
\hline 6 & Acces point & $\begin{array}{l}\text { Tp-LINK, TP-LINK } \\
\text { WA801ND, Indoor }\end{array}$ \\
\hline 7 & Kabel Jaringan & Ethernet, UTP Bilden, Cat 5 \\
\hline 8 & Konektor & Amp Net Connect, RG45 \\
\hline
\end{tabular}

4.2.2 Analisis Kebutuhan Perangkat Lunak (Software).

Adapun kebutuhan perangkat lunak yang akan yaitu sebagai berikut :

Tabel 4.2 Spesifikasi Perangkat Lunak

\begin{tabular}{|c|l|l|}
\hline NO & \multicolumn{1}{|c|}{$\begin{array}{c}\text { Perangkat Lunak } \\
\text { yang digunakan }\end{array}$} & \multicolumn{1}{|c|}{ Spesifikasi } \\
\hline 1 & Sistem Operasi & Windows Server 2012 \\
\hline 2 & Sistem Operasi Client & Windows 7, Windows 8 \\
\hline 3 & Browser & $\begin{array}{l}\text { Firefox, Crome, Spark } \\
44.23\end{array}$ \\
\hline 4 & Simulator & Cisco Paket Tracer 7.0 \\
\hline 5 & Router Controller & Winbox 2.2 \\
\hline 6 & Aplikasi Monitoring & $\begin{array}{l}\text { Wifi } \\
\text { MICKHMON }\end{array}$ \\
\hline 7 & Aplikasi Virtual & virtualbox-5-2-22 \\
\hline
\end{tabular}

4.2.3 Analisis Kebutuhan Pengguna (User).

Adapun kebutuhan pengguna pada jaringan komputer di SD Negeri 2 Sumbawa adalah sebagai berikut:

a. Admin (yang bertugas sebagai pengelola)

b. Client. (yang bertugas sebagai pengguna)

Adapun client atau pengguna jaringan pada SD Negeri 2 sumbawa besar berjumlah 170 client dibagai menjadi beberapa client seperti:

1) Staf : terdiri dari Kepala Sekolah, karyawan tata usaha (TU), karyanan Perpustakaan.

2) Guru : terdiri dari guru Pegawai Negeri Sipil (PNS) dan honorer.

3) Siswa : terdiri dari siswa siswi kelas 45 dan enam.

4) Tamu.

\subsubsection{Analisis Kebutuhan Data Dan Layanan.}

Dalam melakukan penelitian ini peneliti membutuhkan data jumlah siswa, jumlah tenaga pendidik dan tenaga kependidikan, layanan yang biasanya diakses melalui internet. dan kegiatan digitalisasi yang pernah dilakukan diuraikan dalam tabel sebagai berikut:

Tabel 4.3 Kebutuhan Data

\begin{tabular}{|c|c|c|}
\hline No & Data & Jumlah \\
\hline 1 & $\begin{array}{l}\text { Siswa SD Negeri } 2 \\
\text { Sumbawa Besar }\end{array}$ & 536 orang (kelas I - kelas VI) \\
\hline 2 & $\begin{array}{l}\text { Siswa yang } \\
\text { mengakses jaringan }\end{array}$ & $\begin{array}{l}88 \text { orang (kelas IV), } \\
92 \text { orang (kelas V), } \\
102 \text { orang (kelas VI) }\end{array}$ \\
\hline 3 & $\begin{array}{l}\text { Tenaga pendidik, } \\
\text { tenaga kependidikan }\end{array}$ & 32 orang \\
\hline 4 & $\begin{array}{l}\text { Layanan yang biasa } \\
\text { diakses siswa di } \\
\text { internet }\end{array}$ & Youtube,Edmodo,Seamolec \\
\hline 5 & $\begin{array}{l}\text { Layanan yang biasa } \\
\text { diakses guru dan staf } \\
\text { di internet }\end{array}$ & $\begin{array}{l}\text { Youtube, Edmodo, Seamolec, } \\
\text { Whatapp, Facebook, Instagram, } \\
\text { Dapodik }\end{array}$ \\
\hline 6 & $\begin{array}{l}\text { Aktifitas digitalisasi } \\
\text { yang dilaksanakan }\end{array}$ & $\begin{array}{l}\text { Kelas Digital, Ulangan Online, } \\
\text { Tryout Online, Belajar Daring, } \\
\text { Workshop Online }\end{array}$ \\
\hline
\end{tabular}

\subsection{Desain}

Dalam perancangan jaringan komputer SD Negeri 2 Sumbawa Besar dijabarkan menjadi tiga bagian yaitu perancangan infrastruktur jaringan komputer, perancangan sketsa sekolah dan penempatan perangkat jaringan komputer, dan perancangan penggunaan IP address, berikut adalah perancangan dari tiap bagian:

\subsubsection{Perancangan Infrastruktur Jaringan Komputer.}

Merancang infrastruktur jaringan komputer dibagi menjadi empat bagian, pertama rancangan 
infrastrtuktur (topologi) jaringan keseluruhan, kedua rancangan topologi jaringan ruangan lab komputer, ketiga perancangan jaringan kantor dan keempat perancangan jarinngan outdoor. Adapun perancangan infrastruktur jaringan komputer secara keseluruhan menggunakan topologi tree pada SD Negeri 2 Sumbawa Besar dengan gambar sebagai berikut:

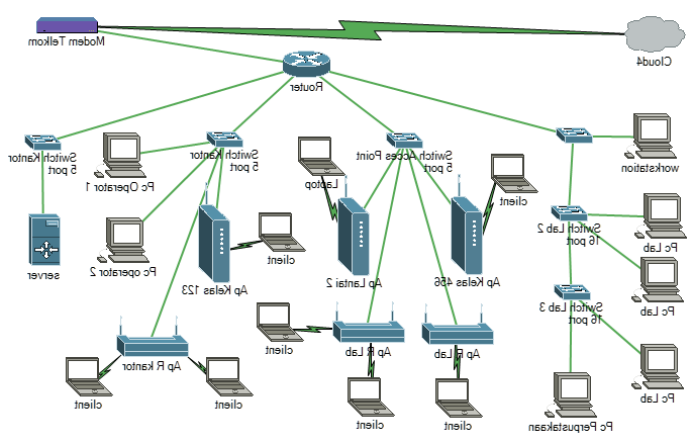

Gambar 4.1 Perancangan Infrastruktur Jaringan

Dalam mengintegrasikan seluruh titik jaringan komputer pada SD Negeri 2 Sumbawa Besar digunakan topologi jaringan komputer dalam bentuk tree yang dikelola oleh admin IT sekolah, melalui menajemen jaringan yang baik seluruh bagian yang ada di sekiolah dapat terhubung pada jaringan komputer pusat yang ada di ruangan lab komputer sehingga seluruh pengguna dapat memanfaatkan penggunaan jaringan komputer secara merata.

\subsubsection{Perancangan Sketsa Sekolah dan Posisi Jaringan Komputer}

Penempatan jaringan komputer di SD Negeri 2 Sumbawa Besar berdasarkan kebutuhan pengguna dibagi menjadi beberapa tempat seperti : ruang lab komputer (tempat praktikum siswa), ruang kantor, ruang guru dan perpustakaan, untuk itu dirancang penempataan (spoting) perangkat jaringan pada lokasi tersebut dan digambarkan dalam bentuk sketsa.

Selanjutnya sketsa penempatan AP pada masing masing bagian terdiri dari tiga AP sektoral dan tiga AP omni .

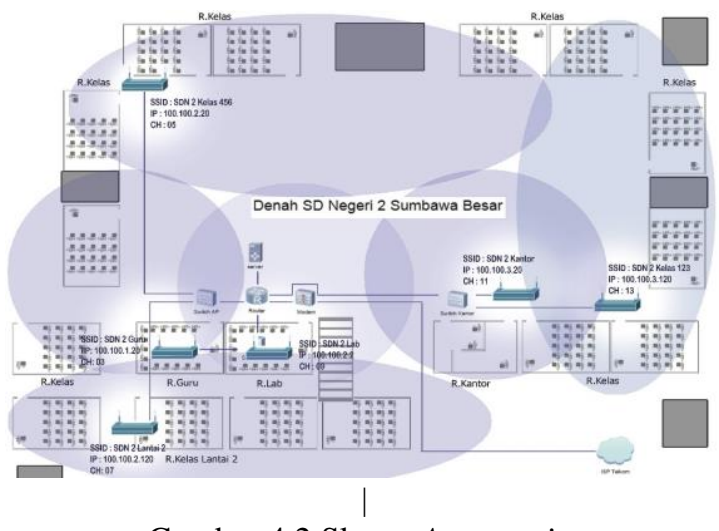

Gambar 4.2 Sketsa Acces point

\subsubsection{Desain Penggunaan IP Address.}

Pembagian IP address mengunakan IP address kelas C yaitu IP 192.168.1.0 Clasless Inter Domain Routing (CIDR) 24 subnetmask 255.255.255.0 yang merupakan ip privat dari Internet Service Propider (ISP) modem telkom. Sementara untuk IP yang akan melayani jaringan local menggunakan IP address kelas C yaitu IP 200.200.200.0 dengan CIDR dan subnetmask yang ditentukan melalui metode Variable Length Subnet Mask (VLSM) Hal ini bertujuan agar mengurangi trafic broadcast, penggunaan IP lebih efisien, memudahkan dalam administrasi/pengelolaan, dan lebih aman lebih aman. Berikut pembagian IP address mengunakan VLSM.

Jaringan Komputer di SD Negeri 2 Sumbawa Besar akan dibangun untuk mengkoneksikan beberapa jaringan komputer seperti jaringan lab komputer memiliki 35 komputer, jaringan acces point untuk mengcover semua areal sekolah yang dipasang sebanyak 6 unit, jaringan kantor dan jaringan server. yang dengan total keseluruhan client yang akan mengunakan jaringan sesuai analisis data pengguana yaitu 170 client, dengan IP 200.200.200.0. Menghitung jumlah host dengan urutan dari yang terbesar dengan metode VLSM digambankan dalam tabel berikut:

Tabel 4.4 Pembagian Jumlah Host Pada Jaringan

\begin{tabular}{|c|l|c|l|}
\hline No & Nama Jaringan & $\begin{array}{c}\text { Jumlah } \\
\text { Host }\end{array}$ & Lokasi \\
\hline 1 & Hotspot & 80 & $\begin{array}{l}\text { Seluruh areal } \\
\text { sekolah }\end{array}$ \\
\hline 2 & Lab Komputer & 48 & Ruang lab komputer \\
\hline 3 & Kantor & 30 & Ruang kantor \\
\hline 4 & Server & 2 & Khusus server \\
\hline
\end{tabular}

Panggunaan IP addres kelas C 200.200.200.0 setelah dilakukan VLSM menghasilkan 4 segmen jaringan dengan CIDR /25 $/ 26 \quad$ /27 dan /30 digunakan sesuai dengan kebutuahan jaringan sehingga penggunaan IP address dapat diefisiensikan dan berikut tabel penggunaan IP address secara keseluruhan :

Tabel 4.5 Penggunaan IP Address Secara Keseluruhan

\begin{tabular}{|l|l|l|l|c|}
\hline \multirow{2}{*}{ Jenis IP } & \multicolumn{4}{|c|}{ Jaringan } \\
\cline { 2 - 5 } & Hotspot & $\begin{array}{c}\text { Lab } \\
\text { Komputer }\end{array}$ & Kantor & $\begin{array}{c}\text { serve } \\
\boldsymbol{r}\end{array}$ \\
\hline Subnet & 200.200. & 200.200 .20 & 200.200. & 200.2 \\
& 200.0 & 0.128 & 200.192 & 00.20 \\
& & & & 0.224 \\
\hline
\end{tabular}




\begin{tabular}{|l|l|l|l|l|}
\hline $\begin{array}{l}\text { Host } \\
\text { pertama }\end{array}$ & $\begin{array}{l}200.200 . \\
200.1\end{array}$ & $\begin{array}{l}200.200 .20 \\
0.129\end{array}$ & $\begin{array}{l}200.200 . \\
200.193\end{array}$ & $\begin{array}{l}200.2 \\
00.20 \\
0.225\end{array}$ \\
\hline $\begin{array}{l}\text { Host } \\
\text { Terakhir }\end{array}$ & 200.200. & 200.200 .20 & 200.200. & 200.2 \\
& & 0.190 & 200.222 & 00.20 \\
& & & & 0.226 \\
\hline $\begin{array}{l}\text { Broadcas } \\
t\end{array}$ & 200.200. & 200.200 .20 & 200.200. & 200.2 \\
& & 0.191 & 200.223 & 00.20 \\
& & & & 0.227 \\
\hline
\end{tabular}

Tabel diatas menunjukan clasifikasi penggunaan IP address dari masing-masing jaringan dengan jaringan 1 untuk internet, jaringan 2 pada lab komputer, jaringan 3 pada acces point,

\subsection{Simulasi}

Dalam penelitian ini menggunakan simulator Cisco Paket Tracer 7.0 dimana proses simulasi dalam Cisco Paket Tracer terdapat sejumlah besar model elemen jaringan, dan memiliki berbagai kemampuan jaringan yang nyata dalam konfigurasinya. Hal ini membuat simulasi jaringan sesuai dengan kenyataan, Simulator memungkinkan untuk menggabungkan beberapa tingkatan atribut dan membuat skema jaringan sesui dengan disain dan diimplementasi dalam lab sebelum ke perangkat fisik. Simulasi dilakukan dengan tahap sebagi berikut:

\subsubsection{Jaringan Komputer Secara Keseluruhan.}

Membangun sisi Server dan Client pada simulator paket tracer menggunakan semua komponen yang dibutuhkan ssesuai perancangan yang telah dibuat pada tahap desain kemudian diimpelementasikan dengan simulator untuk mengetahui hasil konektifitas jarinan sebelum dimimplementasikan di lapangan. Berikut hasil dari simulasi:

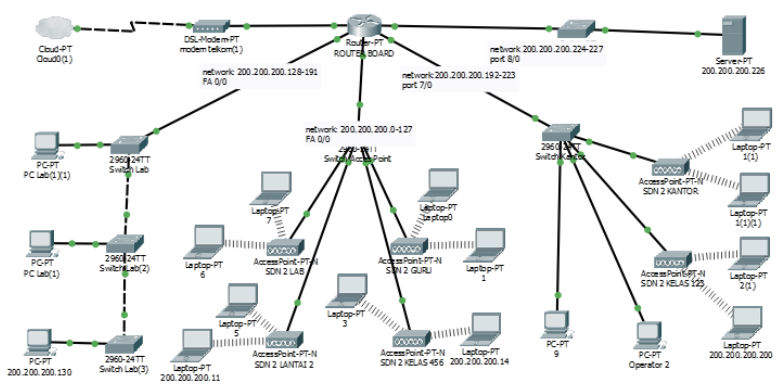

Gambar 4.3 Membangun Jaringan Dengan Paket Tracer

Gambar diatas menunjukan semua perangkat yang terhubung dan sudah dalam keadaan hidup ditandai dengan lampu indikator berwarna hijau pada tiap-tiap koneksi yang ada sehingga semua perangkat jaringan yang tersentralisasi pada router board yang terdiri dari beberapa segmen jaringan berdasarkan pemetaan IP address.

\subsection{Implementasi}

\subsubsection{Pembangunan Fisik.}

Sentralisasi jaringan SD Negeri 2 Sumbawa Besar terdapat di LAB komputer sehingga dalam perancangan dan pembangunan fisik di konsentrasikan pada Lab Komputer yang kemudian dikoneksikan ke bagian bagian lain yang sesuai dengan skema jaringan yang telah di rancang. Berikut gambar persiapan alat yang digunakan.

Pemasangan jaringan diawali dengan penarikan kabel dari modem menuju Mikrotik pada port satu, port ke dua digunakan untuk menghubungkan Mikrotik dengan jaringan switch lab komputer, port tiga digunakan untuk menghubungkan Mikrotik dengan switch acces point, port ke empat digunakan untuk menghubungkan Mikrotik dengan switch kantor dan port ke lima digunakan untuk menghubungkan Mikrotik dengan komputer server.

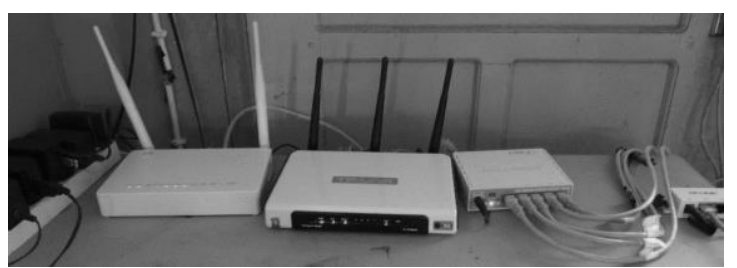

Gambar 4.4 Modem Dan Mikrotik

a. Pembangunan jaringan pada lab komputer.

Jaringan pada lab komputer diinstal terdiri dari server, dan 35 unit PC yang disambung menggunakan kabel LAN, pada yang dikoneksikan menggunakan satu switch inti dan dua switch cabang.

Untuk switch inti terdiri dari 16 port, 10 port terhubung ke 10 Client PC, dan port lainya terhubung ke switch cabang, acces point ruang guru, router dan untuk cadangan. Switch cabang pertama terdiri dari 16 port , 15 port terhubung ke 15 Client Laptop dan satu port tersambung ke switch inti dan switch cabang kedua terdiri dari 16 port , 10 port perhubung ke client, satu port tersambung ke ruang perpusatakaan dan tersambung ke switch inti, sementara sisanya sebagai cadangan.

b. Pembangunan jaringan ruang kantor.

Jaringan pada ruang kantor terhubung dengan switch 5 port . yang terhubung ke dua client(operator), dua acces point (ruangan kepala sekolah dan depan ruang kelas 3 A.) dan ke router yang ada di runngan lab komputer. Berikut adalah gambar hasil pemasangan switch dan acces point yang terdapat pada ruang kantor:

c. Pembangunan jaringan acces point outdoor.

Pemasangan acces point pada jaringan komputer di SD Negeri 2 sumbawa dibagi menjadi dua yaitu indoor dan outdoor. acces point indoor dengan bentuk antena omni (antena dengan daya pancar $360^{\circ}$ ). Yang terpasang di ruangan lab kompuer, 
ruang guru dan ruang kantor. Sementara outdoor dalam bentuk antena sektoral yang terpasang di depan kelas 3 A, 6 C dan lantai 2.

\subsubsection{Konfigurasi}

Konfigurasi jaringan SD Negeri 2 Sumbawa dilakukan terhadap beberapa perangkat jaringaan yaitu Router , server , Client , dan Acces point. Berikut penjabaran dari 4 konfigurasi tersebut.

a. Konfigurasi Router.

Dalam melakukan konfigurasi router digunakan aplikasi winbox sebagai sofware konfigurasi mikroti router board.

1) Penamaan interface

Dilakukan penamaan masing masing interface sesui dengan disain sebelumnya yaitu ether 1 untuk modem, ether 2 untuk lab komputer, ether 3 untuk acces point, ether 4 untuk kantor dan ether 5 untuk server.

2) Pemberian IP Address pada masing-masing interface.

Pemberian IP address digunakan untuk menggolongkan jaringan menjadi beberapa bagian, dan pada penelitian ini jaringan dibagi menjadi 5 berdasarkan IP address yang digunakan pada desain IP.

3) Tes koneksi antar jaringan.

Setelah konfigurasi IP address dilakukan pada masing-masing interface maka dilakukan pengujian di dalam router terhadap IP address yang sudah dimasukan sebelumnya dengan perintah ping.

4) Penambahan IP gateway.

IP gateway diinput dalam konfigurasi untuk memberi aksees kepada semua jaringan yang ada supaya bisa terkoneksi dengan jaringan external (internet).

5) Konfigurasi Domain Name Server (DNS).

Konfiguasi DNS dilakukan dengan menginput IP address gateway.

6) Konfigurasi hotspot login.

Hotspot login dikonfigurasi agar setiap client yang masuk kedalam jaringan terdata dan hanya user name dan password yang telah diinputkan kedalam router saja yang bisa mengakses jaringan. Konfiguari hotspot dilakukan pada menu IP > Hotspot dan selanjutnya pada hotspot Setup untuk mengatur yang dimulai dengan hotspot interface diisi dengan port yang akan menggunakan hotspot. Port interface lab komputer, port interface hotspot dan port interface kantor menggunakan user nama dan passwor serta hotspot untuk login sehingga dilakukan konfigurasi pada tiap port. local address network merupakan IP dari masing masing port interfece dan diisi sesuai interface nya. Address pool of nerwork diisi dengan range IP yang akan digunakan oleh jaringan hotspot tersebut. DNS Server tetap diisi dengan IP gatway jaringan internet yaitu 192.168.1.1 dan DNS name diisi dengan nama DNS yang akan dipanggil oleh browser saat pertama kali login yang kemudian menampilkan halaman web login hotspot. Hal itu dilukuan secara berulang dan disesuakan dengan interface yang membutuhkan user login.

Pada pengguna jaringan yang terkoneksi melalui ethernet 2 lab komputer, ethernet 3 hotspot, ethernet 4 kantor akan melakukan login pada halawan hotspot yang telah dibuat dengan DNS www.sdn2sbw.com akan tampil seperti gambar berikut ini:

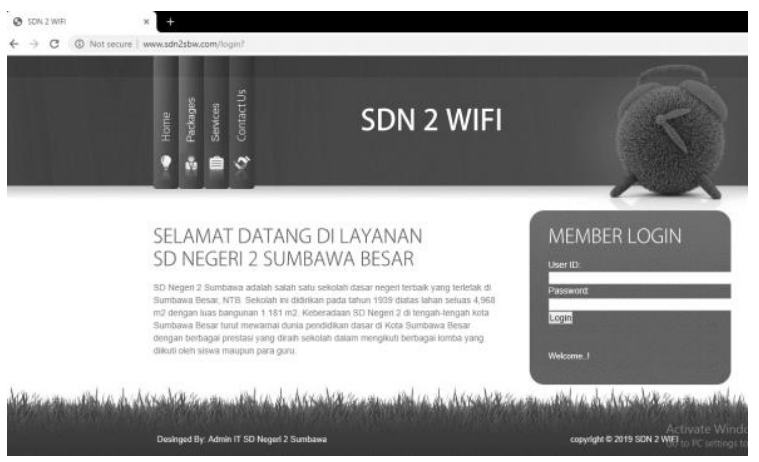

b. Konfigurasi server.

Dalam penelitian ini digunakan windows server 2012. Hal ini dilakukan karena server akan melayanai atau menjadi pusat kegiantan digitalisasi SD Negeri 2 Sumbawa Besar. Didalamnya akan terinsatal aplikasi aplikasi yang menjadi sentral kegiatan sekolah seperti pusat data, monitoring, dan aplikasi ujian siswa berbasis jaringan komputer. diawali dengan instalasi os windows server. Setelah instalasi dilakukan maka akan tampil halaman inti dari window server 2012 yang akan di konfigurasikan yaitu halaman server manager seperti gambar berikut:

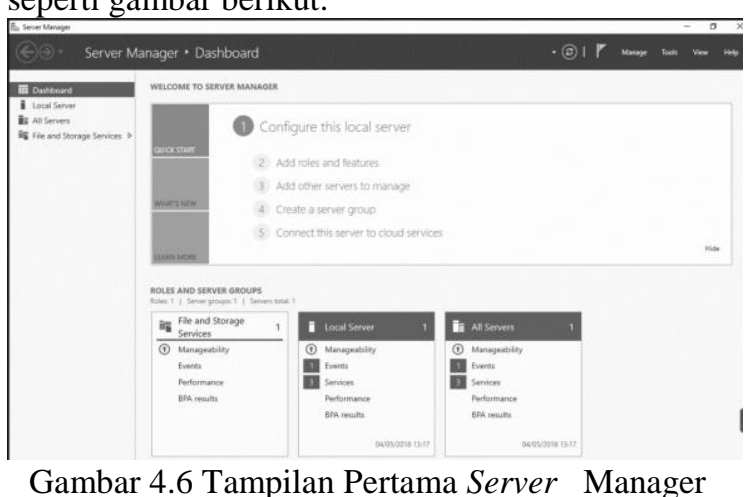

Pada poin sebelah kiri hanya terdapat empat item yaitu dashbord, local server, all server, dan file and storage service. Semuanya belum diaktifkan termasuk acctive directory. Untuk pertama dilakukan perubahan nama server

Konfigurasi dilakukan pada local server, general name, dan computer name. Yang dilanjutkan dengan konfigurasi acctive directory. Pada menu manage, 
add role and fieture.Dalam konfigurasi active directory akan melewati bebrapa halaman seperti yang terlihat pada gambar yaitu halaman before you begin dilanjutkan, halaman instaltion type dipilih role base or feature base instalation, halaman server selectioan dipilih select a server from the server pool, halaman server roles dicentang active directory domain server, halaman feture dicentang group police management dan dilakukan instalasi sampai selesai.

c. konfigrasi Acces Point.

Dalam melakukan konfigurasi acces point yang terdiri dari enam acces point dan tersebar di berbagai lokasi di SD Negeri 2 Sumbawa dengan keterangan dalam tabel sebagai berikut:

Tabel 4.6 Pembagian Posisi Dan Keterangan Acces Point.

\begin{tabular}{|l|l|l|l|l|}
\hline No & SSID & IP Address & Ch & Lokasi \\
\hline 1 & SDN 2 Guru & 200.200 .200 .10 & 03 & R.Guru \\
\hline 2 & Lab Komputer & 200.200 .200 .20 & 05 & R.Lab \\
\hline 3 & SDN 2 Lantai 2 & 200.200 .200 .30 & 07 & L. 2 \\
\hline 4 & SDN 2 Kelas 456 & 200.200 .200 .40 & 09 & K. 6 C \\
\hline 5 & SDN 2 Kantor & 200.200 .200 .50 & 11 & Kantor \\
\hline 6 & SDN 2 Kelas 123 & 200.200 .200 .60 & 13 & K. 2 A \\
\hline
\end{tabular}

Pada masing masing acces point dibedakan Service Set Identifier (SSID) hal ini untuk memudahkan masing masing user dalam mengakses jaringan, dan juga kebutuhan client untuk membedakan penggunaan dari pada jaringan tersebut, selanjutnya konfigurasi pada salah satu acces point dengan langkah sebagai berikut. Akses browser pada PC kemudian pada Uniform Resource Locator (URL) diisi sesua dengan alamat IP defoult dari pada acces point dengan IP address 192.168.0.254 dan user name serta passwor adalah admin. Memilih network kemudain Lan untuk dilakukan penggantian IP Address dengan 100.100.2.20 dan subnetmask serta gateway seperti gambar berikut:

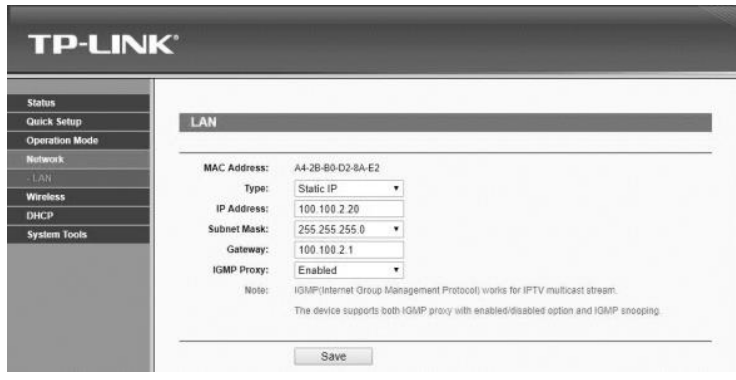

Gambar 4.7 Tampilan Acces point TP-Link Menu LAN.

Setelah semua poin sudah terisi pada menu Network LAN maka settingan di restar untuk mengaplikasikan konfigurasi pada perangkat.
Konfigurasi manual dilakukan perubahan IP pada PC dengan IP dalam jaringan yang sama yaiti 200.200.200.21 agar bisa terkoneksi dengan cara masuk ke Kontrol Panel / Network and Internet / Network and Sharing Center / ethernet / ethernet proberti / IP Versi 4 dan dilakukan konfigurasi.Setelah konfigurasi IP Address dilakukan maka acces ponint bisa diakses seperti sebelumnya. Selanjutnya perubahan SSID, Lokasi, Channel, perubahan user name dan password dari admin menjadi sdn2. Hal ini dilakukan untuk antisipasi gangguan dari pihak yang tidak diingainkan terhadap acces point sehingga kenapa perlu diubah dari settingan default.

d. Konfigurasi Client.

Pada client dilakukan konfigurasi pada control panel, network and internet, network konectian, dan melakukan konfiguarsi pada ethernet, propertis, IP versi 4 dan memilih obtain an IP address automatically untuk memperoleh IP melalui DHCP server dan memilih wifi jika mengunakan perangkat nirkabel.

\subsection{Monitoring}

\subsubsection{Monitoring Koneksi.}

Monitoring koneksi dilakukan dengan cara tes ping antara server, router, dan client serta internet dengan sampel pengujian pada seluruh IP ethernet pada port 1, port 2, port 3, port 4, dan port 5 dengan hasil pengujian koneksi atara jaringan dengan internet yang di ping melalui router sebagai berikut:

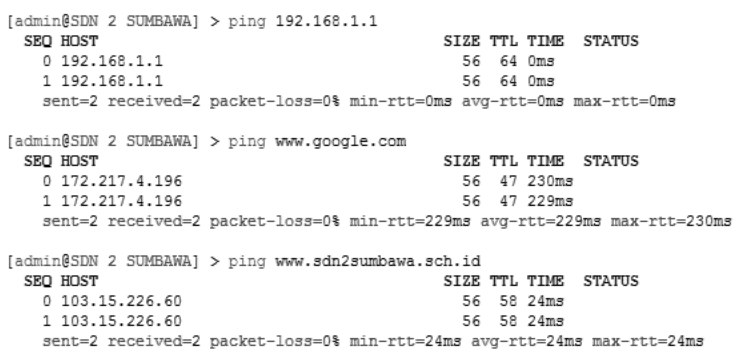

\section{Gambar 4.8 Hasil Pengujian Koneksi Dari Router} Ke Internet

Pada saat ping dilakukan oleh router ke gateway yang ada pada modem dengan IP 192.168.1.1 maka hasilnya adalah waktu pengiriman $0 \mathrm{~ms}$ dengan jarak pengiriman antara satu paket dengan paket lainya 64 sedangkan ukuran paket hanya 56 byte. Sementara untuk tes koneksi dengan www.google.com memperoleh IP 172.217.4.196 dengan waktu pengiriman paket 230 ms. Pengujian dilakukan dari router ke salah satu host yang aktif yaitu dengan IP 200.200.200.219 yang terkoneksi pada jaringan kantor dengan hotspot port 4 kantor maka hasilnya sebagai berikut. 


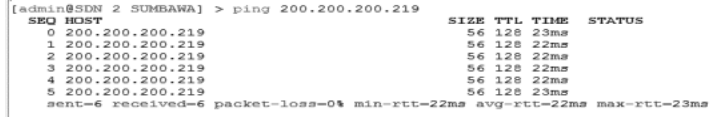

Gambar 4.9 Tes Koneksi Ke Client

\subsubsection{Monitoring Traffic.}

Traffic monitoring dilakukan dengan memonitoring jaringan melalui melihat dari traffic pada jaringan dan menghasilkan laporan berdasarkan traffic jaringan.

Berikut hasil dari monitoring pada masingmasing port pada jaringan:

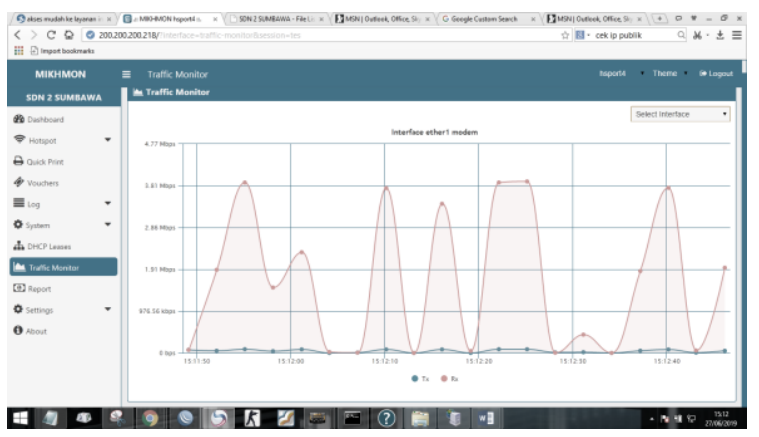

Gambar 4.10 Monitoring Pada Port 1 Yang Terkoneksi Ke Modem

Dari gambar diatas terliah receiver $(\mathrm{Rx})$ yang berwarna merah lebih besar dari transmiter (Tx) yang berwarna iru. Hal ini disebabkan karena port 1 merupakan gateway antara jaringan local dengan jaringan public. Artinya semua akses data dari client yang terdapat pada semua jaringan menuju ke internet menggunakan jalur port 1 dengan IP 192.168.1.1. selanjutnya untuk visualisasi traffic dari port 2 port 3,4 dan port 5 yang merupakan port dengan jaringan berbeda seperti port 2 untuk jaringan lab komputer, port 3 untuk jaringan hotspot, port 4 untuk jaringan kantor dan port 5 untuk komputer server.

\subsubsection{Monitoring Acces point.}

Sebagaimana pada proses imlementasi AP yang terdiri atas 6 perangkat yang dipasang dengan SSID yang berbeda sehingga pada saat monitoring jaringan dengan posisi admin berada pada titik sentral SD Negeri 2 Sumbawa menggunkan aplikasi Wifi Analizer dan terlihat seperti gambar berikut:

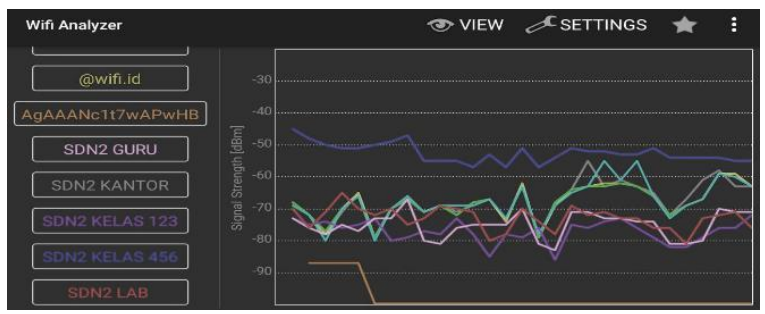

Gambar 4.11 Hasil Monitoring AP
Bagian sebelah kiri menunjukan SSID yang gambarkan dengan warna yang variatif sesui dengan list grafik yang berada di sebelah kanan. Semakin rendan nilai grafik maka semakin kecil kekuatn signal

\subsection{Manajemen}

\subsubsection{Manajemen Kesalahan (Fault Management).}

Pada bagian menajemen kesalahan, admin melakukan pengecekan perangkat dan aktifitas jaringan untuk mengetahui kesalahan (fault) pada perangkat yang dikelola, jaringan, dan operasi jaringan, sehingga admin dapat segera menentukan apa penyebabnya dan dapat segera mengambil tindakan (perbaikan).

\subsubsection{Manajemen Konfigurasi (Configuration Management).}

Memonitor informasi konfigurasi jaringan dilakukan admin sehingga dampak dari perangkat keras atau pun lunak yang digunakan jaringan SD Negeri 2 Sumbawa Besar telah terkelola dengan baik. Hal tersebut dilakukan dengan inisialisasi, konfigurasi ulang, pengoperasian, dan mematikan perangkat yang dikelola secara berkala.

Inisialisai dilakukan pada semua perangkat jaringan, seperti inisiasi router, server , client , acces point, hotspot server . Pada router inisialisasi dilakukan pada perangkat dan pada masing masing port router disesuaikan dengan tujuan port tersebut. Pada router dikonfigurasi dalam setingan sistem $>$ identity $=S D N 2$ $S U M B A W A$, sedangkan port dikonfigurasi pada interface $>$ ethernet $>$ name $=($ sesuai interface $)$. Inisiasi pada perngakat lain telah dilakukan seperti dilaporkan pada tahap monitoring, semua perangkat terbaca sesuai dengan namanya baik itu client maupun server adan acces point.

\subsubsection{Management Pelaporan (Accounting).}

Managemen pelaporan dilakukan oleh admin SD Negeri 2 Sumbawa untuk mengukur utilisasi jaringan dari pengguna atau grup tertentu untuk menghasilkan informasi penggunaan data serta melakukan pengaturan pengguna sesusi dengan tinggatnya sehingg performa jaringan bisa terjaga dengan baik. Pembagian dilakukan berdasarkan tingkat kebutuhan jaringan seperti: admin 2 user dengan rate limit upload/download (Up/Down) = $5 \mathrm{~m} / 5 \mathrm{~m}$, staf 10 user dengan rate limit $U p /$ Down $=$ $5 \mathrm{~m} / 5 \mathrm{~m}$, guru 30 user dengan rate limit $U p /$ Down $=$ $4 \mathrm{~m} / 4 \mathrm{~m}$, siswa 100 user dengan rate limit Up/Down $=2 \mathrm{~m} / 2 \mathrm{~m}$, tamu 10 user dengan rate limit Up/Down $=1 \mathrm{~m} / 1 \mathrm{~m}$

4.6.4 Manajemen Performa (Performance Management). 
Dalam proses manajemen performa jaringan admin mengukur berbagai aspek dari performa jaringan termasuk besar bandwith yang diperoleh dari ISP sehingga dapat dikelola. Dalam hal ini admin melakukan testing pada perangkat jaringan melalui speed tes.

\subsubsection{Manajemen Keamanan (Security}

Management).

Dalam hal ini admin melakukan Pengaturan akses ke sumber daya jaringan sehingga informasi tidak dapat diperoleh tanpa izin. Hal tersebut dilakukan dengan cara: memberikan user name dan password pada masing masing client yang terkoneksi ke jaringan sebagaimana dijelaskan dalam gambar 4.44 User list. Untuk mencegah masuknya pengguna yang tidak bertanggung jawab ditetapkan penggunaan IP seefisien munggkin menggunakan metode subneting dan VLSM agar tidak terjadi pemborosan IP address seperti terlihat pada rancangan Tabel 4.14 Penjabaran jumlah host yang ada pada keseluruhan jaringan. Selanjutnya dilakukan manajemen keamanan router sebagai perangkat sentral yang mengatur lalu lintas data dan koneksi jaringan

\section{PENUTUP}

\subsection{Kesimpulan}

Dari hasil analisis dan perancangan jaringan yang telah dilakukan sebelumnya dengan menggunakan metode Network Development Life Cycle (NDLC) maka penulis dapat mengambil kesimpulan bahwa Analisis Dan Pengembangan Infrastruktur Jaringan Komputer Dalam Mendukung Implementasi Sekolah Digital (Studi Kasus SD Negeri 2 Sumbawa Besar) telah selesai dibangun menggunakan perangkat router, switch, acces poin, server, dan aplikasi pendukung lainnya, sehingga dapat dilakukan penyebaran informasi dan pertukaran data melewati jaringan, pengolaan jaringan menggunakan mikhmon dan terdapat sentral penyimpanan data pada server. Dengan demikian penelitian ini dapat memberikan konstribusi untuk membantu menjalankan salah satu misi SD Negeri 2 Sumbawa Besar yaitu membimbing dan mengembangkan kemampuan ilmu pengetahun dan teknologi bagi seluruh warga sekolah.

\subsection{Saran}

Dari hasil analisis dan pengembangan infrastruktur jaringan komputer dalam mendukung implementasi sekolah digital (studi kasus SD Negeri 2 Sumbawa Besar), penulis memberikan saran agar pada tahap selanjutnya dilakukan pengembangan jaringan untuk memperoleh kinerja yang lebih baik antara lain meliputi:

1) Dapat dilakukan pengembangan infrastruktur jaringan komputer dengan merancang proses yang lebih baik lagi dengan mengganti perangkat router, switch dan acces point menggunakan cisco.

2) Dapat dilakukan upgrade kabel LAN dari kategori 5 menjadi kategori 6.

3) Dapat dilakukan pengembangan konfigurasi jaringan pada router agar kontrol jaringan bisa dilakukan dari luar, atau public.

4) Dapat menggunakan aplikasi yang lebih advance dalam pengoaan dan monitoring jaringan seperti aplikasi solarwin sebagai pengganti mickhmon

\section{REFERENSI}

Esabella, Shinta. (2016). Perancangan Infrastruktur Jaringan Komputer Untuk Mendukung Implementasi Sistem Informasi Pada Universitas Teknologi Sumbawa. Sumbawa: Universitas Teknlogi Sumbawa.

Harahap, Sofyan Safri, (2004). Analisis Kritis Atas Laporan Keuangan. Jakarta:PT. Raja Grafindo Persada.

Kodoatie, Robert J.(2005).Pengantar Manajemen Infrastruktur.Yogyakarta: Pustaka Pelajar.

Kristanto, Andi, (2003).Jaringan Komputer. Yogyakarta: Graha Ilmu

Mahmud, Dr. Muchammad Eka (2017). Mengembangkan Sekolah Digital Di Era Globalisasi. Samarinda: (FTIK) IAIN Samarinda.

Surjadi. (2012). Pengembangan Kinerja Pelayanan Publik. Bandung :Refika Aditama.

Usman, Nurdin. (2002) Konteks Implementasi Berbasis Kurikulum. Jakarta: PT.Raja Grafindo Persada. 